\title{
Color semantics: linguistic-cultural aspect
}

\author{
Shara Mazhitayeva, Zhanar Kaskatayeva \\ Karaganda State University named after academician E. A. Buketov, Karaganda, Kazakhstan \\ Email address: \\ Sh-mazhit@inbox.ru(S. Mazhitayeva)
}

To cite this article:

Shara Mazhitayeva, Zhanar Kaskatayeva. Color Semantics: Linguistic-Cultural Aspect. International Journal of Language and Linguistics. Vol. 1, No. 1, 2013, pp. 34-37. doi: 10.11648/j.ijl1.20130101.15

\begin{abstract}
The color is of great importance in the life of modern man. The basic condition of communication considered background knowledge, i.e. knowledge of the realities and cultures who mutually enjoyed talking and listening. A comparative study of ways to describe colors in different languages is one of the traditional topics of Linguistics. This article discusses the phraseological units, containing in its semantics element color designations. On the material of the Kazakh attempts to uncover the meanings of some of the color names as an important phenomenon, capturing the essence of the language of the ethnic group.
\end{abstract}

Keywords: Meanings and Symbols, World of Colors, Phraseological Units with Color Naming Components, National Psychology, Peculiarities of Mentality

\section{Introduction}

Color has a great role in modern human being's life. The main condition of efficient communication between people is being familiar with background knowledge, i.e., realms and traditions of each other which are possessed by both speaker and listener. Comparative analysis identifying ways of color naming in different languages is one of the traditional linguistic themes for investigation. Color is objectified in a language with the help of a group of lexical units - color naming, that is why color namings permanently attract linguists' attention investigating mechanisms of world categorization by people and being one of the most investigated notions in different languages.

Our investigation is devoted to color linguistics not at random. The similar investigations of this type were made earlier in the sphere of humanitarian and natural sciences. Nevertheless nowadays investigations concerning color spectrum are still urgent and demanding for many scholars. Scholars have already made researches on the content of color naming vocabulary in psycholinguistic aspect (A.P.Vasiliyevich), semantic structure (A.A. Bragina, I.V. Mokiyenko), stylistic functions of color namings were investigated in psycholinguistic description (P.V. Alimpiyeva), color naming intensity was investigated on a base of comparative-historical analysis (N.B. Bakhilina), psycholinguistic experiment was conducted (L.V. Vasiliyevich, R.M. Phrumkina). Linguistic consciousness of people, colors' role in human beings' vital activities, in ethno cultural system of Russian language are being investigated by T.I. Vendina.

Investigation of culture and its verbalization in a language has got special attention. W. von Humboldt in his popular work "Comparative anthropology" states importance of investigating culture in a view of different language groups, view of objective reality from different sides, and various ways of representing linguistic world view in the history of development of civilization. In relation to it, investigation of "human spirit" image in a language, in traditions, customs, myths, i.e., analysis of perception, cognition, reflection and emotional attitude of a person toward the world is still urgent problem in our days[1, p.85]. In Kazakhstan linguistics the notion of the color is mainly investigated by Ph.N. Dauletov, A.T.Kaydarov, D.A. Kazhygaliyeva whose works are devoted to the analysis of ethno-linguistic, linguistic culturological peculiarities of color namings. One of the latest researches of Kazakhstan linguists in a field of color naming is the research of many years by Sh.K.Zharkynbekova named as "Color concepts in Kazakh and Russian linguistic cultures"[2].

Investigation of theoretical aspects of color linguistics is closely connected with scientific trend of "color linguistics". Linguists distinguish comparative-historical investigation of color vocabulary (evolutionary trend),psycholinguistic component of color namings, cognitive aspects, linguistic-cultural and nominative-term formation aspects of investigation of color vocabulary. 
Special interest of scholars to this sphere of scientific researches accounts for the existence of such notions as "color linguistics", "color semantics", "figurative linguistics", "linguistic-color world view" and etc.

So, analysis of theoretical material on problems of investigating color namings has proved that color linguistics as an independent scientific discipline has its own firm theoretical and methodological base. In this case it is hard to disagree with V.G. Kulpina's opinion which is following: "Concept of color linguistics as an independent scientific paradigm in modern linguistics gains more and more concrete and obvious features"[3, p.7].

The basic object of investigation is both sayings and phraseological units, and lexical semantic group of color namings in Kazakh language. The active development in modern linguistics of such trends as cognitive linguistics, psycholinguistics, and linguistic cultural science gave opportunity to scholars to investigate language facts in their relation to people's national values, culture, religion, mental make-up, mental and world outlook peculiarities. Recently investigations of color namings in the sphere of linguistic cultural science paradigm gained special actualization. Advanced usage of linguistic cultural science interpretation method gives opportunity to sufficiently objectively re-establish those semantic transformations reflecting naive world view corresponding to this or that epoch, reconditioning mental sets of world outlook system as a whole.

Significance of color semantics as culture component has complicated and various sacral system of senses, interpretations for every nation and becomes embodiment of definite cultural values. Consequently, color namings can be represented as linguistic cultural phenomenon[4, p. 48].

Linguists, ethno linguists came to the single conclusion that color namings have some universal similarities. E.M.Vereshagin, V.G. Kostomarova give very important opinion in their popular work devoted to linguistic-cultural theory of word which states that figurative expressions, idioms and proverbs are used for certain colors and its various shades. They can represent information about past social-historical, emotional-mental state of each nation[5, $\mathrm{p}$ 67]. Some scholars suppose that use of identical color namings in lexical and phraseological units of different languages arises due to the usage of the main and significant colors in ethnos's life: "Prevalence of one and the same color namings in lexical and phraseological units of different languages refer to the fact that they are the main and the most necessary colors of certain ethnic community: "If we want to understand each other, such words as black, white, red, yellow, green, blue are sufficient for expressing our feelings" $[6, \mathrm{p} .16]$.

According to the researches of A.T. Kaydarov, A.T. Umirbekov, Z.T. Akhtamberdiyev who investigated color namings in Kazakh language, there are no pure colors without admixtures except white and black. Analyzing colors inherent in steppe fauna, scholars were convinced in the necessity of using "the main color" and "its shades" on tradition, besides, by conducting experience, they found out that mixture of the main seven (or ten) colors in different amounts and correlations contributes to the formation of separate certain colors[7, p.45]. In accordance with A.T. Kaydarov's opinion who investigated color namings in Kazakh language from the new side, there are more than 150 color namings in Kazakh language consisting of one syllable, formed by the principle of relying on the subject base[8, p.53]. They are blood-red, cherry-red, bright red, gold yellow, sky-blue, iron-black and etc. The scholar supposes that there will be further enrichment in the structure of compound adjectives in Kazakh language expressing complex shades of color spectrum. By the way, there are also adjectives in Russian language formed by the given model: coffee-colored, blood-red, milky, light green, light violet, brick red, sky-blue, mustard-yellow and etc. Anyway, according to the scholar's opinion they are less in Kazakh language.

The earliest researches on studying color namings semantics in Turkic languages were works of academician A.N. Kononov. The following works of A.N. Kononov are devoted to studying the given problem: "On the semantics of the words "white" and "black" in Turkic geographical terminology", "Semantics of color namings in Turkic languages" in which semantics of the words "white" and "black" are examined, that occur in geographical terminology of Turkic languages, also connotation peculiarities of those are considered there. In the abovementioned works author investigates the ways of color namings composition and their meanings in the language of Turkic people.

\section{Research Objectives}

The present article has the following objectives:clarifying scientific conclusionsserving as methodological bases of the research; -the analysis of meanings of color naming in Kazakh and Russian languages and their semantic differences in translation.

The research subject consists of phraseological expressions, catchwords and expressions including color denotations of the Kazakh language: blue, brown, yellow, red, black, white which attract researchers' interest by means of group of lexical units, the names of color.

In this article we will consider semantics of some of these colors.

Descriptive and etymological methods are used as basic research methods. The method of description and interpretation were used to describe linguistic studies. Methods of componential and comparative analyses were used to establish the semantics of color naming.

Similar to other languages Kazakh language word combinations related to color naming can be considered in the following groups as nature, human being, social-public system, traditions and customs, rituals and etc. For Kazakh people were nomad nations in ancient times, their life activities were closely connected with nature. The aim of 
nomad people was not about subduing the nature, on the contrast people tried to live peacefully with the nature, such comprehension came with an experience, and thus moral, cultural and ethical principles emerged. Besides direct meaning of the color, there is its indirect meaning, for instance, white color in Kazakh language means humaneness, innocence, good intentions, justice, truth, kindness, prosperity, holiness and the current color is known as generous, worthy, pleasant, and warm color. ... Even though I'm honest, you want to slander me? Tell me, if he is not honest! What will you say if he turns out to be honest, innocent[9, p. 87]. Opposite to white is black color.

A.N. Kononov being the first who investigated meanings of color namings in Turkic languages distinguished 20 different meanings of black color as an adjective. The black color means not only darkness, piercing cold, dense, large, strong, fierce, mass, ordinariness, uncertainty, but also hardship, difficult anxiety, poverty. Some scholars consider names related to black color dividing them on 6 groups: 1) evil; 2) crime, cruelty; 3) priority; 4) holiness, kindness; 5) simplicity; 6) grief and despondency[10, p.63]. One more meaning of black color is connected with beauty: Blackeyed, Black-haired. Moreover, black color is treated as natural color: color of the earth, sign of prosperity. This is philosophical notion meaning constancy, statics: "naked earth", "common people", "matchlock gun", "black horse", "maid who does spade work".

In ancient Turkic language the color was able to identify the world's side: red symbolized - south, black - north, white - west, blue -east. For the red is considered to be flame-colored, sunny sign, it is also considered to be holy color. In ancient times Kazakh people followed such customs as worshiping the sun, that is why symbol of the sun was tabooed: they didn't talk about fire, they didn't spitted on the fire, they didn't put out a fire with the water, they didn't trampled down ashes, made purification ceremony with the help of fire. Flaming campfire in the hearth under the yurta's (nomads' tent) dome was the sign of unity, prosperity, continuation of the kin; as the result of it such words as youth yurta, young family, family emerged. In modern Kazakh language the color "red" was the base for the origin of such words as blush, young, animated, beautiful girl[11, p.43].

In Kazakh culture blue color means calmness and unity, prosperity and life. Blue - an equivalent to the word creator, maker, thus this color means strength, victory, high spirit, superiority, arrogance. Blue - name of people, space, everlasting universe, which contain stars, constellations, planets, and galaxy. Blue - ancient Turkic kosmonim[11, p.51]. Blue color often occurs in national ornaments, minarets' cupolas of both Turkic and Kazakh people which witnesses that blue color has a special symbolic meaning.

Brown color stands for steadiness, composure, politeness. Such word combinations as everyday deals, late fall, pleasant wind, pleasant tender song, pleasant voice with the seme as brown color have the next meanings: normal, one and the same, favorable, and positive. ... Pleasant sound from far away as mother's cradle rocks everlasting steppe to sleep[12, p.246]. Zerre called his grandchild ...... and said: -Aynalayin, konyrkozym (literally: my sweet, my brown lamb) - and stroked on his back[9, p. 298].

Yellow color is an indication of intelligence, satisfaction, restraint: such expressions as patient will be rewarded one day or another, hope is the last thing to die with the use of vocabulary meaning yellow color - on the one hand provides with consolation and hope, on the other hand it is connected with grief, melancholy and despondency: give way to deep despair, be sad, besides in the meaning of duration - wait fora long time; also in the meaning wide, large, huge.

In Kazakh language motley colors are wide spread in a great deal of indirect meanings, and referring to the group of white color shades they can have meaning of white, pale, yellow, grey, light red, light yellow, light grey, grayish, yellowish; to the group of black-brown color - shades of black, brown, bay, dark bay, brownish black and etc., as a result of mixing such colors various color gamut emerged[13, p.88].

A. Margulan explains the symbolic values of all colors: blue color - it is a symbol of sky and cleanness; red- it is a symbol of fire and sun; white - it is a symbol of happiness, gladness, truth; yellow color - it is a symbol of mind; black - it is a symbol of land; but green - it is a symbol of spring and youth. Every folk have the concepts about colors. For example, in our people a white color symbolizes by gladness, prosperity, honesty; but black color symbolizes by contrary, grief, cruelty, misery[14, p.17].

It is undoubtedly that besides the main ways of word formation with the meaning of color naming in national traditions, there are both universal color categories as white and black, and colors which have various lexical semantic symbolical sense for different nations. It is obvious and known that the given meaning is passed on from one generation into another. Colors in various languages due to their symbolical features, nowadays have other meanings which have no relations to color or have distant semantic linkage to the color.

We attempted to make small scientific investigation concerning color semantics in comparative analysis. We tried to reveal the meaningfulness of the most significant colors in Kazakh culture basing on the materials of Kazakh belles-lettres which give opportunity to reflect peculiarity of linguistic consciousness of the ethnos and originality of national culture which cannot be represented without color spectrum[15,pp. 1084-1087; pp.1772-1775].

When describing the appearance of the hero,for example, whendescribingthe outline ofthe girl's face, aswritersusually take3 colorsincorporated inthe nationalknowledge of the world: white, black, red. Here are someexcerpts: "Showingwhite teeth, the expression of an openface, causing the whole bodyflinch, with thecourtesy ofattractingattention.... round eyes as currant,which concealsa quietmystery,....itsattractiveredfaceshiningfrom above..(A. Sejdimbekov,Akkyz). " "...A pointednose, 
andeyes like black currants. Hairandpouring.Forreal,asdescribedin the tales ofBeauty"(SundetovMagzom. Shaitan bazar).

As the previous examples show us, Kazakh people described the face of a beautiful girl like an inspiring, brilliant, bright which concern the bright skin of girl. And the most beautiful eyes were deep black and brown eyes. The words which in Russian are used as the model of beauty like "blood and milk, blue-eye" have meaning of white, red, and yellow (gold). And in Kazakh language for portraying girl's quality used 3 or more colors: black eye, black currant eye, eye like sheep, eye like coal, black hair like silk, white face, face like snow, white throat, red lips.In the conscious of folk white, black, red colors mean the beauty, youth. For example, if the girl's eyes were big and black, such eyes were compared with currant. M. B. Abdrakhmanova in her scientific work proved that the "currant" used to show such quality like beautiful, attractive, kind. Researcher during the analyzing the concept "see" gave following definitions to the black color: 1) beautiful, 2) nice, 3) attractive, 4) kind, 5) happy, 6) attaching, 7) deep, 8) clear, 9) fragile [16,p.11].

Nevertheless, these colors also can give another different meaning. There are a lot of examples in the works of great writers and authors, where all the colors used in a different way for reaching defined style. For instance, in the works by Abai white color means intellect, yellow - wealth, red easy virtue

Also we daily often use a word "black eye" for the beautiful woman, and writers in descriptions uses instead of white color - black.

\section{Conclusion}

In conclusion, we find out the traditions, costums, mentality, character by form of color symbols that get implanted of every nations the ethnic's world of view. In future we consider versatile researching using terms of word explanations and forms of colors in literature language. Such a proceedings is very important and useful to translate works from one language to another.

Our research let us make a conclusion that color semantics in linguistic culture of the Kazakh language cannot be always adequately translated into Russian language, the ways of formation of figurative expressions are different from each other in Kazakh, Russian and German languages, nuclear and peripheral component don't always correspond to each other and can be different which is historically defined by living circumstances of people.

\section{References}

[1] W. von Humboldt, "Selected works on linguistics".M.: Progress, 1984, 396 p.

[2] Sh.K. Zharkynbekova, "Color-consciousness-mentality. Reconstruction of color view of the world in Kazakh and Russian linguistic cultures". Monograph. Astana: PO master, 2011,357 p.

[3] V.G. Kulpina, "Theoretical aspects of color linguistics as scientific trend of comparative linguistics" Dissertation abstract... Phd-s of philological sciences.M., 2002, 49 p.

[4] L. Bayramova, "Social-linguistic nomination with color lexems. Word. Text. Time. New means of linguistic nomination in new Europe"// Materials of VII intern. scient. confer/edited by M. Alekseyenko, M. Kuchinska-Shetsin, 2004, 478 p.

[5] E.M. Vershagin, V.G.Kostomarov, "Linguistic cultural theory of the word". M: Russkiyyazik publishing house, $1980,320 \mathrm{p}$.

[6] G.K. Kortobayeva, "Kazakh onomapoetry: satirical humorous names of personages. Candidate's dissertation abstract. Almaty, 2007, 30 p.

[7] A. Kaydarov, B.Umirbekov, Z.Akhtamberdiyeva, Colors full of mystery. Almaty: Kazakhstan, 1986, 95 p.

[8] A. Kaydar, Urgent problems of Kazakh language. Almaty, 1998, 304 p.

[9] M. Auezov, Collected works issued in 20 vol., v.3, "Abai". Novel-epopee, Almaty: Zhazushy, 1979, 424 p.

[10] A. Kononov, "On semantics of the words "white" and "black" in Turkic geographical terminology" proceedings of Science Academy, Tajikistan SSR, common sciences department. Issue V, 1954, pp. 81-86; Semantics of color naming in Turkic languages. // Turkic collected works, M., 1975, pp.145-153.

[11] Y. Baran, M. Zimomrya, O. Bilous, I. Zimomrya, "Phraseology: signs and sizes":[textbook for students of foreign language faculties], Vinnytsia: Nova Kniga, 2008, $256 \mathrm{p}$.

[12] G. Mustaphin, Collected works issued in 5 vol., v.5, Almaty, 1981, 384 p.

[13] R. Laulanbekova, "Color naming in complex nominations (based on adjectives and nouns)", Candidate's dissertation abstract, Almaty, 2010, 29 р.Пожалуйста, подождите

[14] A. Margulan,“Kazakh folk applied art”,v.1 Almaty, 1982. $256 \mathrm{p}$.

[15] Sh. Mazhitaeva, Zh. Talaspaeva, A. Tazhikeyeva, "Connotation of color namings in Kazakh language", European Resercher, 2012, vol. 25, 7, pp. 1084-1087;Sh. Mazhitaeva, Zh. Kaskataeva, "Lexical and symbolic meaning of some colors in Kazakh Language", European Resercher. 2012, vol. 32, 10-2, pp. 1772-1775.

[16] Abdrakhmanova M. B.,"Concept «Eyes»: linguocultural and cognitive paradigm”, Author's abstract (of dissertation ). Almaty, 2008.25p. 